\title{
Engagement in business simulation games: A self-system model of motivational development approach
}

\author{
Isabel Buil $^{\text {a }}$ \\ Sara Catalán ${ }^{\mathrm{b}}$ (corresponding author) \\ Eva Martínez ${ }^{\mathrm{c}}$
}

a: Faculty of Business and Economics of the University of Zaragoza. María de Luna, s/n

- Edificio "Lorenzo Normante" - 50018, Zaragoza, Spain. E-mail: ibuil@unizar.es.

b: Faculty of Business and Economics of the University of Zaragoza. Gran Vía 2, 50005, Zaragoza, Spain. E-mail: scatala@unizar.es.

c: Faculty of Business and Economics of the University of Zaragoza. Gran Vía 2, 50005, Zaragoza, Spain. E-mail: emartine@unizar.es.

Accepted for publication in British Journal of Educational Technology

Acknowledgments: This work was supported by the Government of Spain (ECO201782103-P), and the Government of Aragón and the European Social Fund (project Generés S54_17R and pre-doctoral grant BOA 28/08/2014). 


\title{
Engagement in business simulation games: A self-system model of motivational development approach
}

\begin{abstract}
This research draws on the self-system model of motivational development to explain how the use of business simulation games in class facilitates students' engagement and enhances their learning. Based on a survey of 360 undergraduate students who played a business simulation game in a marketing course, the findings show that students' perceptions of competence, autonomy, relatedness and self-efficacy have a positive impact on their cognitive, emotional, and behavioural engagement. In addition, cognitive and emotional engagement have a positive influence on skills development and perceived learning.
\end{abstract}

Keywords: competence; autonomy; relatedness; self-efficacy; engagement; business simulation games

\section{Introduction}

Engagement in the academic context has received great attention among scholars and educators for its potential to increase learning (Skinner, 2016), academic achievement (Zumbrunn et al., 2014), persistence in learning (Fredricks et al., 2004), performance (Green et al., 2012) and satisfaction (Filak and Sheldon, 2008). However, recent studies have noticed a decline in students' motivation, engagement and enjoyment over time (Furrer et al., 2014). Indeed, student disengagement is considered as one of the main problems in the OECD (Organization for Economic Co-operation and Development) learning systems (Hamari et al., 2016).

While students are little motivated by traditional classes, they are more often so in game-based settings (McGonigal, 2011). Therefore, in order to solve the problems associated with lack of motivation and engagement, recent studies have suggested gamifying learning aspects (Hamari et al., 2016), making academic activities more fun, interesting and appealing to students. 
An effective teaching tool that motivates and engages players actively in the learning experience is business simulation games (Vos and Brennan, 2010). Business simulation games are virtual representations of real business situations that allow players to manage a company in a risk-free environment. By providing a context in which players are "learning by doing” (Caulfield et al., 2012), business simulation games offer an effective alternative to traditional teaching methods (Ben-Zvi, 2010) in disciplines such as marketing and management. Previous research has shown that positive benefits can derive from the use of business simulation games (Sitzmann, 2011), such as enhanced player interest in the management field (Loon et al., 2015) and improved learning experiences (Matute and Melero, 2016). Business simulation games have been also related to the development of numerous skills, such as decision-making, team working, working under pressure and adapting to new situations (Fitó-Bertrán et al., 2014; Loon et al., 2015; Pasin and Giroux, 2011). Similarly, they have been associated with increased learning in relation to understanding how business decisions are made in the real world (Vos and Brennan, 2010) and with an understanding of the practical integration of business functions (Borrajo et al., 2010; Fitó-Bertrán et al., 2014).

Although previous studies have recognised the benefits deriving from business simulation games, little is known about what factors make business simulation games successful (Matute and Melero, 2016). Drawing on the self-system model of motivational development (Connell and Wellborn; 1991; Skinner et al., 2008), this study investigates how the use of business simulation games promotes students' engagement. In particular, we postulate that students' perceptions of competence, autonomy, relatedness and self-efficacy while playing business simulation games promote their cognitive, emotional, and behavioural engagement. In addition, we look at the outcomes derived from the students' engagement. In particular, we hypothesise that the cognitive, emotional and behavioural engagement experienced while playing business simulation games will facilitate the development of various work-related skills and perceived learning.

This study contributes to the extant literature in different ways. First, we advance knowledge in the field by analysing business simulation games through the self-system model of motivational development. This model offers an interesting framework for the study of engagement. However, although previous research provides empirical support for the model (e.g., Dupont et al., 2014; Fall and Roberts, 2012; Skinner et al., 2008; 
Zumbrunn et al., 2014), the evidence is limited in the context of business simulation games. Therefore, drawing on the self-system model of motivational development, this study sheds new light on the processes that promote students' engagement while playing business simulations games, by analysing the impact of individual factors on engagement and the effects of engagement on students' outcomes. Second, compared to the study of motivation, research into engagement is a relatively young area (Skinner, 2016). In addition, most engagement studies have not considered the multidimensional nature of the construct, which includes cognitive, emotional and behavioural components (Wang and Peck, 2013) and relatively few have focused on higher education (Zumbruun et al., 2014). To address these gaps, this research examines the multiple dimensions of engagement among undergraduate students. Finally, the results can help both academia and educators understand how business simulation games should be used to improve students’ engagement and learning outcomes.

\section{Business simulation games}

Business simulation games are training tools based on simulated environments representing real business situations. Whereas failure in a real business setting would have direct negative consequences for an organisation, these virtual worlds allow players to manage a company within a safe environment (Galea, 2001), fostering learning.

The functioning of business simulation games provides an overall view of corporate strategic functions. While simulations in other fields are primarily aimed at developing specific skills, business simulation games provide training in various functions (e.g. production, R\&D, marketing, accounting and finance), which helps the players to understand their interrelationships.

Due to their nature, business simulation games represent an effective alternative to traditional teaching methods (Ben-Zvi, 2010). Business simulation games help players to understand how business decisions are made in the real world (Vos and Brennan, 2010) and to develop a holistic view of the functioning of a manufacturing company (Lainema and Nurmi, 2006). Similarly, they have been associated with enhanced performance (Pasin and Giroux, 2011) and heightened interest in the management field (Loon et al., 2015). 
Business simulation games are also an effective tool to help players develop the generic and specific managerial competencies that are highly valued in the business world (Borrajo et al., 2010; Doyle and Brown, 2000). For instance, they are useful for developing generic competences, such as information processing and analysis, decision making, communication skills and working with uncertainty (Fitó-Bertrán et al., 2014; Loon et al., 2015; Pasin and Giroux, 2011). Playing business simulation games also improves problem solving, team working and adaptation to new situations (Borrajo et al., 2010). Regarding specific managerial skills, playing business simulation games can increase one's understanding of the fundamentals of business administration and the relationship between business units and organisational functions, help in strategy development and, in general, help to meet company goals (Borrajo et al., 2010; FitóBertrán et al., 2014).

\section{Theoretical framework and research hypotheses}

\subsection{Student engagement}

The concept of student engagement has attracted increasing attention over recent years (Lei et al., 2019; Xie et al., 2019) due to its potential predictiveness of students' learning outcomes, such as course grades, participation in class, academic achievement, course completion, reduced dropout rates, or satisfaction (Connell and Wellborn, 1991; Fall and Roberts, 2012; Filak and Sheldon, 2008; Fredricks et al., 2004; Reeve, 2013).

Overall, the student engagement literature is characterised by a lack of consensus. First, as noted by Christenson et al. (2012), there is no agreed standard definition of engagement. Secondly, although it seems that researchers agree that engagement is a multidimensional construct (Fredricks et al., 2004), there has been some variation in the number and type of dimensions included within the construct (Fredricks and McColskey, 2012). Some scholars have suggested that engagement includes behaviour and emotion (Skinner et al., 2009b), whereas others have proposed a three-dimensional model including behaviour, emotion and cognition (Fredricks et al., 2004; Fredricks and McColskey, 2012; Henrie et al., 2015; Lei et al., 2019; Skinner, 2016; Xie et al., 2019). Additional dimensions such as agentic engagement (Reeve and Tseng, 2011) have also been considered. Finally, another area of debate in the field of engagement is related to whether information about engagement should be provided by students, teachers, or 
through classroom observation (Skinner, 2016), as well as if it should be measured with self-reported survey data or not (Xie et al., 2019) (see Fredricks and McColskey (2012) and Henrie et al. (2015) for a review on operationalisations and measures of student engagement).

In an attempt to address some of these definitional issues, Sinclair et al. (2003) recommended distinguishing between the facilitators of engagement and the indicators of engagement. Facilitators of engagement are the external causal factors that facilitate or undermine engagement (Skinner et al., 2008). They can be divided into different classes (Skinner, 2016). The first class focuses on individual factors or features of the self that promote engagement. These factors are also known as self-perceptions, selfappraisals and self-systems, and include variables such as feelings of belonging, selfefficacy and values. The second class of engagement facilitators focuses on social contexts and relationships that promote engagement, and includes variables such as support from parents, teachers and peers, school climate and the nature of academic work (Connell and Wellborn, 1991; Skinner, 2016). Indicators of engagement are internal features of the construct of engagement (Skinner et al., 2008). As mentioned earlier, it is widely accepted that the main indicators of engagement are cognitive, emotional and behavioural engagement (Fredricks et al., 2004). Cognitive engagement is the student's level of investment in learning, such as understanding what is being taught. Emotional engagement refers to the feelings that learners have about the learning experience, such as interest, enjoyment, boredom and frustration. Finally, behavioural engagement includes participation, attendance, effort expenditure and persistence (Fredricks et al., 2004).

\subsection{The self-system model of motivational development}

The self-system model of motivational development (Connell and Wellborn, 1991; Skinner et al., 2008), a framework grounded in the self-determination theory (Deci, 1975), provides a theoretical basis for understanding the processes by which social contextual factors impact on students' self-system processes and subsequent engagement and achievement. The model suggests that fundamental human needs competence, autonomy and relatedness -, which are also central to the selfdetermination theory, are the basis for the development of self-system processes (Connell and Wellborn, 1991). Briefly, competence refers to the experience of behaviour as effective and masterful (White, 1959). It is related to the need for 
challenge and the ability to produce desired outcomes. Autonomy refers to the experience of one's behaviour as choiceful (de Charms, 1968). This relates to the desire to self-organise experiences and act in accordance with one's own sense of self. Finally, relatedness refers to the experience of connection with others (Baumeister and Leary, 1995). Accordingly, self-system processes such as sense of competence, sense of autonomy and sense of relatedness result in engagement or disaffection (Connell and Wellborn, 1991). In particular, the model posits that when psychological needs are met, engagement occurs, which is manifested in cognition, affect and behaviour. On the contrary, if psychological needs are not met, disaffection results (Connell and Wellborn, 1991). Additional self-system processes, such as self-efficacy, which refers to belief in one's ability to achieve a desired outcome (Bandura, 1997), are also of real importance (Eseryel et al., 2014; Zumbrunn et al., 2014).

\subsection{Research hypotheses}

Prior research into engagement in academic contexts provides support for the impact of students' self-system processes on engagement. First, perceived competence and autonomy have been associated with different dimensions of engagement, such as cognitive (Skinner et al., 2008), emotional and behavioural engagement (Dupont et al., 2014; Skinner et al., 2008). Connell and Wellborn (1991) also found that children with reported higher levels of autonomy were judged by their teachers to be more engaged in class. Relatedness was also found to be a predictor of emotional and behavioural engagement in elementary/primary school (Skinner et al., 2008) and high/secondary school (Shen et al., 2012). Finally, various studies (e.g. Eseryel et al., 2014; Zumbrunn et al., 2014) have also showed that students with higher self-efficacy tend to have reported higher engagement in class. Accordingly, we hypothesise that students' perceptions of competence, autonomy, relatedness, and self-efficacy while playing business simulation games will have a positive impact on cognitive, emotional, and behavioural engagement.

H1: Satisfaction of the need for competence has a positive impact on (a) cognitive engagement, (b) emotional engagement, and (c) behavioural engagement.

H2: Satisfaction of the need for autonomy has a positive impact on (a) cognitive engagement, (b) emotional engagement, and (c) behavioural engagement. 
H3: Satisfaction of the need for relatedness has a positive impact on (a) cognitive engagement, (b) emotional engagement, and (c) behavioural engagement.

H4: Self-efficacy has a positive impact on (a) cognitive engagement, (b) emotional engagement, and (c) behavioural engagement.

As previously noted, engagement has been found to be a robust predictor of students' learning (Fredricks et al., 2004; Reeve, 2013). Connell and Wellborn (1991) found that teachers' reports of students' engagement in school were directly related to academic achievement and grades. Similarly, academic and behavioural engagement in high/secondary school were associated with greater achievement and decreased likelihood of dropping out of school (Fall and Roberts, 2012). Similarly, previous research has associated cognitive, emotional, and behavioural engagement with important academic outcomes, such as academic achievement (Fredricks et al., 2004) and satisfaction (Filak and Sheldon, 2008).

Previous studies have suggested that business simulation games help students to develop various skills (Borrajo et al., 2010; Doyle and Brown, 2000). These skills can be divided into generic competences, such as analysing information, decision making, team-working, problem solving and communication skills (Borrajo et al., 2010; FitóBertrán et al., 2014; Loon et al., 2015; Pasin and Giroux, 2011); and specific managerial competencies, such as running a company, understanding the relationships between business units and developing strategies (Borrajo et al., 2010; Fitó-Bertrán et al., 2014). Therefore, we hypothesise that students' cognitive, emotional, and behavioural engagement while playing business simulation games is positively associated with skills development (i.e. generic competences), and perceived learning (i.e. specific managerial knowledge).

H5: Cognitive engagement has a positive impact on (a) skills development, and (b) perceived learning.

H6: Emotional engagement has a positive impact on (a) skills development, and (b) perceived learning.

H7: Behavioural engagement has a positive impact on (a) skills development, and (b) perceived learning.

Figure 1 presents the proposed model underlying this research. 
Figure 1. Proposed model

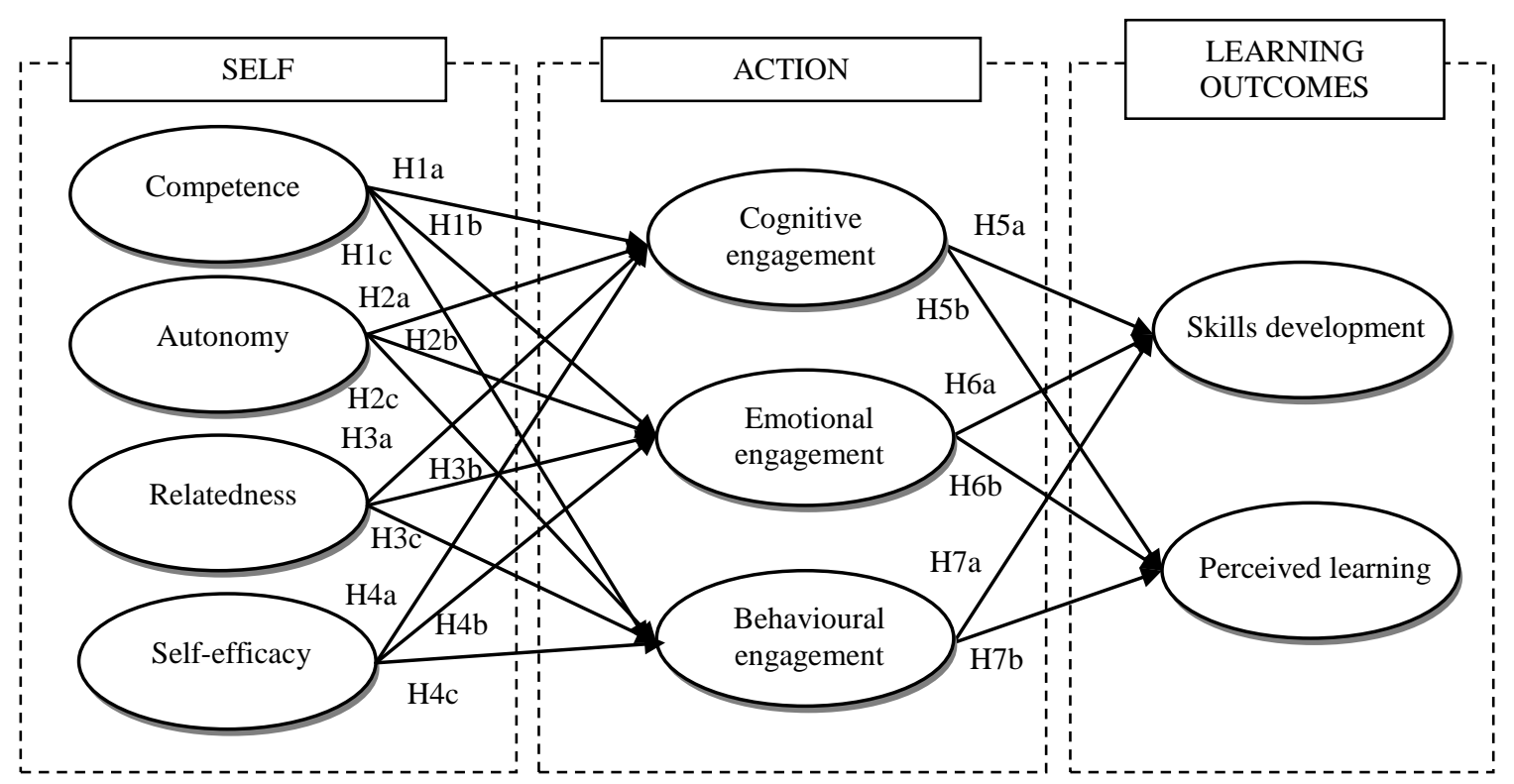

\section{Methodology}

\subsection{Data collection and participants}

The study was carried out in the business faculty of a major Spanish university. The participants were final year students who played a business simulation game in a semester-long marketing course. Data were collected through a self-administered questionnaire at the end of the semester, after the last gaming session. Data from two academic years (2015-16 and 2016-17) were included in the study. Participation was voluntary, and the anonymity and confidentiality of data were guaranteed for the 360 students who answered the questionnaire.

\subsection{Procedure}

This study employed a business simulation game developed by the Spanish simulation developer Gestionet S.L. During the first sessions, the students were taught the objective and operation of the business simulation game and how to use the software. After familiarising themselves with the simulation game, students were divided into teams of 4-6 members. Each team was in charge of managing a company to compete against companies run by other students. The game included ten rounds of decisionmaking.

The students had to manufacture and sell various air-conditioning products in different markets. Similarly, students had to deal with inventory, quality control, outsourcing, 
purchasing of new machinery and human resources management. The students also had to make decisions on marketing areas, such as pricing, distribution, and media planning, and to manage the company's finances.

Based on decisions made and results obtained, the simulation game gave a total score to each group, up to maximum of 1,000 points. This score was complemented with feedback received about market share, from positioning studies and financial statements, among other reports. Based on all this information, the students evaluated their strategy and recalibrated it for the following round.

\subsection{Measurement instrument}

To measure the constructs included in the model, we employed well-established scales taken from previous literature. The need for competence, autonomy and relatedness were measured using the Player Experience of Need Satisfaction (PENS) scale, developed by Ryan et al. (2006). The specific items were adapted from Neys et al. (2014), who applied the PENS scale in a videogame setting. The measures of selfefficacy were adapted from the Motivated Strategies for Learning Questionnaire, developed by Pintrich et al. (1991). Cognitive engagement was measured following the Metacognitive Strategies Questionnaire (Wolters, 2004) and emotional and behavioural engagement were measured in accordance with Reeve (2013). To measure skills development, we selected various - decision making, working under pressure, teamwork and applying theory into practice - which had been highlighted in previous studies as the most important skills acquired when playing business simulation games (Borrajo et al., 2010; Fitó-Bertrán et al., 2014; Loon et al., 2015). Finally, perceived learning was measured using items from Tiwari et al. (2014), assessing students' perceptions about how helpful the business game is in helping them understanding the integration of business functions, the analysis of competitive advantages, target markets, or product positioning. In all cases, seven-point Likert scale items were used, ranging from 1 (strongly disagree) to 7 (strongly agree).

Table 1 provides an overview of the measures. 
Table 1. Constructs, items, and measurement model results

\begin{tabular}{|c|c|c|c|}
\hline Constructs and items & FL & $\mathbf{C R}$ & AVE \\
\hline Competence & & 0.949 & 0.862 \\
\hline COM1.I feel competent at the business game & 0.927 & & \\
\hline COM2.I feel very capable when playing the business game & 0.938 & & \\
\hline COM3.I feel effective in the business game & 0.920 & & \\
\hline Autonomy & & 0.906 & 0.762 \\
\hline AUT1.I experienced a lot of freedom in the business game & 0.847 & & \\
\hline AUT2.The business game provides me with interesting options and choices & 0.902 & & \\
\hline AUT3.I could always find something interesting in the business game to do & 0.869 & & \\
\hline Relatedness & & 0.923 & 0.800 \\
\hline REL1.I find the relationship with my group mates gratifying & 0.897 & & \\
\hline REL2.I find the relationship with my group mates important & 0.909 & & \\
\hline REL3.I feel close to my group mates & 0.878 & & \\
\hline Self-efficacy & & 0.884 & 0.717 \\
\hline $\begin{array}{l}\text { Before playing the business game... } \\
\text { SELF1.I believed I would receive an excellent grade } \\
\text { SELF2.I was confident I could learn interesting concepts } \\
\text { SELF3 I expected to do well }\end{array}$ & $\begin{array}{l}0.871 \\
0.851 \\
0.818\end{array}$ & & \\
\hline Cognitive engagement & & 0.890 & 0.729 \\
\hline $\begin{array}{l}\text { When I am playing the business game... } \\
\text { COG1.I try to connect it with what I am learning through my degree } \\
\text { COG2.I try to make all the decisions fit together and make sense } \\
\text { COG3.I try to relate what I am learning to what I already know }\end{array}$ & $\begin{array}{l}0.842 \\
0.838 \\
0.880 \\
\end{array}$ & & \\
\hline Emotional engagement & & 0.889 & 0.667 \\
\hline EMO1.I feel good & 0.807 & & \\
\hline EMO2.I feel interested & 0.815 & & \\
\hline EMO3.I have fun & 0.860 & & \\
\hline EMO4.I feel involved & 0.784 & & \\
\hline Behavioural engagement & & 0.885 & 0.720 \\
\hline BEH1.I try hard to do well in the game & 0.890 & & \\
\hline BEH2.I participate in group discussions & 0.857 & & \\
\hline BEH3.I listen very carefully to the teacher & 0.795 & & \\
\hline Skills development & & 0.907 & 0.660 \\
\hline SD1.Decision-making & 0.846 & & \\
\hline SD2.Working under pressure & 0.817 & & \\
\hline SD3.Teamwork & 0.827 & & \\
\hline SD4.Applying theory in practice & 0.802 & & \\
\hline SD5.Adapting to new situations & 0.769 & & \\
\hline Perceived learning & & 0.928 & 0.763 \\
\hline $\begin{array}{l}\text { PL1.The business game helped me to understand the integration of business } \\
\text { functions }\end{array}$ & 0.868 & & \\
\hline $\begin{array}{l}\text { PL2.The business game helped me to understand how to analyse competitive } \\
\text { advantages for a business }\end{array}$ & 0.878 & & \\
\hline PL3.The business game gave me a thorough understanding of target markets & 0.867 & & \\
\hline $\begin{array}{l}\text { PL4.The business game gave me a thorough understanding of product } \\
\text { positioning }\end{array}$ & 0.882 & & \\
\hline
\end{tabular}

Note: FL: Standardized factor loading; CR: Composite reliability; AVE: average variance extracted. 


\section{Results}

The hypotheses were tested using partial least squares (PLS). SmartPLS 3.0 software was used (Ringle et al., 2015). In comparison to other structural equation modelling methods, such as the covariance-based structural equation method, PLS, a variancebased structural equation method, is more suitable when the focus is on prediction and theory development (Reinartz et al., 2009) and, as in our case, the conceptual model is complex and includes various indicators and latent variables (Chin, 2010; Hair et al., 2011).

\subsection{Measurement model}

We first assessed the reliability and validity of the constructs. Table 1 shows that all standardised factor loadings were above 0.7 (Carmines and Zeller, 1979), which suggests that individual item reliability was adequate. Moreover, all the constructs were internally consistent, as the composite reliabilities were above 0.7 (Nunnally and Bernstein, 1994). In addition, the constructs met the convergent validity criteria, as the average variance extracted (AVE) values were greater than 0.5 (Fornell and Larcker, 1981). Finally, as shown in Table 2, discriminant validity was also supported. In all cases, the square root of the AVE was greater than squared inter-constructs correlations (Fornell and Larcker, 1981).

Table 2. Discriminant validity

\begin{tabular}{|c|c|c|c|c|c|c|c|c|c|c|c|}
\hline & $\mathbf{M}$ & SD & 1 & 2 & 3 & 4 & 5 & 6 & 7 & 8 & 9 \\
\hline 1. Competence & 5.51 & 1.03 & 0.928 & & & & & & & & \\
\hline 2. Autonomy & 5.51 & 0.95 & 0.546 & 0.873 & & & & & & & \\
\hline 3. Relatedness & 6.28 & 0.82 & 0.341 & 0.449 & 0.895 & & & & & & \\
\hline 4. Self-efficacy & 5.73 & 0.87 & 0.243 & 0.423 & 0.290 & 0.847 & & & & & \\
\hline 5. Cognitive Eng. & 5.66 & 0.81 & 0.434 & 0.484 & 0.380 & 0.350 & 0.854 & & & & \\
\hline 6. Emotional Eng. & 5.82 & 0.79 & 0.602 & 0.645 & 0.482 & 0.408 & 0.585 & 0.817 & & & \\
\hline 7. Behavioural Eng. & 6.14 & 0.76 & 0.408 & 0.508 & 0.527 & 0.396 & 0.669 & 0.520 & 0.849 & & \\
\hline 8. Skills development & 5.61 & 0.87 & 0.502 & 0.612 & 0.450 & 0.399 & 0.492 & 0.700 & 0.601 & 0.812 & \\
\hline 9. Perceived learning & 5.45 & 0.94 & 0.462 & 0.617 & 0.378 & 0.510 & 0.446 & 0.583 & 0.473 & 0.729 & 0.874 \\
\hline
\end{tabular}

Note: M: mean; SD: standard deviation; Values on the diagonal are the square root of AVEs. Offdiagonal elements are the correlations among constructs. 


\subsection{Structural model}

The proposed model was then tested. To assess the significance of the path coefficients, a bootstrapping procedure with 5,000 subsamples was employed. The satisfaction of the need for competence, autonomy and relatedness and self-efficacy accounted for $31.9 \%$ of the variance of cognitive engagement, $55.2 \%$ of the variance of emotional engagement and $40.8 \%$ of the variance of behavioural engagement. Similarly, the model explained $39.6 \%$ of the variance of skills development and $35.8 \%$ of the variance of perceived learning. The Stone-Geisser test criterion $\left(Q^{2}\right)$ exceeded the threshold of 0 for all the dependent variables, supporting the model's predictive relevance.

The results indicate that satisfaction of the need for competence while playing business simulation games was positively and significantly associated with players' cognitive ( $\beta$ $=0.217 ; \mathrm{t}=3.108)$, emotional $(\beta=0.328 ; \mathrm{t}=7.178)$ and behavioural engagement $(\beta=$ 0.136; $\mathrm{t}=2.480$ ), supporting $\mathrm{H} 1 \mathrm{a}, \mathrm{H} 1 \mathrm{~b}$, and H1c respectively. Similarly, as proposed in $\mathrm{H} 2 \mathrm{a}, \mathrm{H} 2 \mathrm{~b}$, and H2c, the satisfaction of the need for autonomy had a positive and significant influence on players' cognitive ( $\beta=0.229$; $\mathrm{t}=3.317)$, emotional $(\beta=0.325$; $t=6.545)$ and behavioural engagement $(\beta=0.208$; $t=3.675)$. The satisfaction of the need for relatedness also had a positive and significant impact on players' cognitive $(\beta=$ $0.158 ; t=2.811)$, emotional $(\beta=0.184 ; t=4.299)$ and behavioural engagement $(\beta=$ 0.335; $\mathrm{t}=6.291$ ), supporting HЗа, H3b, and H3c respectively. The results also show that the players' self-efficacy had a positive and significant influence on their cognitive engagement ( $\beta=0.154 ; \mathrm{t}=2.996)$, emotional engagement $(\beta=0.137 ; \mathrm{t}=3.065)$ and behavioural engagement $(\beta=0.177 ; \mathrm{t}=3.630)$. Therefore, $\mathrm{H} 4 \mathrm{a}, \mathrm{H} 4 \mathrm{~b}$, and $\mathrm{H} 4 \mathrm{c}$ were also supported.

Regarding the influence of players' engagement on their learning outcomes, the results show that players' cognitive engagement positively influenced both their skills development $(\beta=0.171 ; \mathrm{t}=2.371)$ and their perceived learning $(\beta=0.136 ; \mathrm{t}=2.098)$, supporting H5a and H5b. The players' emotional engagement with the business simulation game also predicted their skills development $(\beta=0.425 ; \mathrm{t}=6.247)$ and their perceived learning $(\beta=0.462 ; \mathrm{t}=6.948)$. Therefore, H6a and H6b were supported. However, contrary to our predictions, the players' behavioural engagement did not have a significant effect on their skills development $(\beta=0.108 ; t=1.616)$ or their perceived learning $(\beta=0.059 ; \mathrm{t}=0819)$, so $\mathrm{H7a}$ and $\mathrm{H7b}$ are rejected.

Table 3 presents the results of the structural model. 
Table 3. Structural model results

\begin{tabular}{|llccc|}
\hline & \multicolumn{1}{c}{ Hypothesis } & $\boldsymbol{\beta}$ & t-value & Supported \\
\hline H1a & Competence $\rightarrow$ cognitive engagement & 0.217 & $3.108^{* *}$ & Yes \\
H1b & Competence $\rightarrow$ emotional engagement & 0.328 & $7.178^{* *}$ & Yes \\
H1c & Competence $\rightarrow$ behavioural engagement & 0.136 & $2.480^{* *}$ & Yes \\
\hline H2a & Autonomy $\rightarrow$ cognitive engagement & 0.229 & $3.317^{* *}$ & Yes \\
H2b & Autonomy $\rightarrow$ emotional engagement & 0.325 & $6.545^{* *}$ & Yes \\
H2c & Autonomy $\rightarrow$ behavioural engagement & 0.208 & $3.675^{* *}$ & Yes \\
\hline H3a & Relatedness $\rightarrow$ cognitive engagement & 0.158 & $2.811^{* *}$ & Yes \\
H3b & Relatedness $\rightarrow$ emotional engagement & 0.184 & $4.299^{* *}$ & Yes \\
H3c & Relatedness $\rightarrow$ behavioural engagement & 0.335 & $6.291^{* *}$ & Yes \\
\hline H4a & Self-efficacy $\rightarrow$ cognitive engagement & 0.154 & $2.996^{* *}$ & Yes \\
H4b & Self-efficacy $\rightarrow$ emotional engagement & 0.137 & $3.065^{* *}$ & Yes \\
H4c & Self-efficacy $\rightarrow$ behavioural engagement & 0.177 & $3.630^{* *}$ & Yes \\
\hline H5a & Cognitive engagement $\rightarrow$ skills development & 0.171 & $2.371^{*}$ & Yes \\
H5b & Cognitive engagement $\rightarrow$ perceived learning & 0.136 & $2.098^{*}$ & Yes \\
\hline H6a & Emotional engagement $\rightarrow$ skills development & 0.425 & $6.247^{* *}$ & Yes \\
H6b & Emotional engagement $\rightarrow$ perceived learning & 0.462 & $6.948^{* *}$ & Yes \\
\hline H7a & Behavioural engagement $\rightarrow$ skills development & 0.108 & 1.616 & No \\
H7b & Behavioural engagement $\rightarrow$ perceived learning & 0.059 & 0.819 & No \\
\hline
\end{tabular}

Note: * $\mathrm{p}<0.05 ; * * \mathrm{p}<0.01$.

\section{Conclusions}

Engagement in the academic context has captured great attention among scholars and educators. However, there is a need to investigate further the factors that influence students' engagement while playing business simulation games. With the aim of addressing this gap, this study draws on the self-system model of motivational development (Connell and Wellborn, 1991; Skinner et al., 2008) to analyse the impact of students' perceptions of competence, autonomy, relatedness and self-efficacy, while playing business simulation games, on their cognitive, emotional and behavioural engagement and the influence of engagement on students' skills development and perceived learning.

The results of the empirical study provide strong support for the use of business simulation games as a tool to promote engagement among undergraduate business students. Overall, these findings confirm that self-system processes are essential for the development of greater engagement. More specifically, the findings reveal that students' perceptions of competence and autonomy while playing business simulation games have a positive impact on their cognitive, emotional and behavioural engagement, 
which is in line with previous studies (Dupont et al., 2014; Skinner et al., 2008). In addition, this study advances prior research that had found that perceptions of relatedness are associated with emotional and behavioural engagement (Shen et al., 2012; Skinner et al., 2008), finding also a positive impact on cognitive engagement. Likewise, the findings provide support for the relationship between students' perceptions of self-efficacy and all dimensions of engagement. In particular, the findings show that satisfying the need for competence influences fundamentally the cognitive and emotional dimensions of engagement, as does the need for autonomy. However, the need for relatedness and perceptions of self-efficacy have more impact on the behavioural dimension of engagement.

Several studies have analysed the impact of engagement on different learning outcomes, such as grades (Connel and Wellborn, 1991), academic achievement (Fredricks et al., 2004), or satisfaction (Filak and Sheldon, 2008), Our results advance previous research by providing insights into the effects of each dimension of engagement on skills development and perceived learning. Our findings show that students' cognitive and emotional engagement positively impact on their skills development and perceived learning. In particular, the emotional engagement dimension had the greatest impact of both outcomes, suggesting that being involved with the game and experiencing fun are the main determinants of the success of business simulation games. Finally, although previous research has highlighted the link between behavioural engagement and success in school (e.g., Skinner, 2016), our findings do not provide support for the relationship between behavioural engagement, skills development and perceived learning. An explanation for this could be that students who participated in the study showed higher scores for behavioural engagement than for cognitive and emotional engagement (see Table 2), and with lower deviation. Given that the business simulation game was played in the classroom, they all tried to do well, participated in group discussions and paid attention to the teachers' instructions and comments. Thus, the variation in their perceptions of learning gains and skills development was not a consequence of their behavioural engagement.

This study makes a number of theoretical contributions. First, we analyse the impact of individual factors on engagement in the context of business simulation games and shed new light on the processes that promote engagement in undergraduate students. In addition, to respond to the call for more research into the factors that contribute to the 
success of business simulation games (Matute and Melero, 2016), this study proposes a framework based on the self-system model of motivation development to analyse the engagement experienced by students while playing business simulation games. Finally, while most previous engagement studies have not considered the multifaceted nature of the construct (Wang and Peck, 2013), and only a few have focused on higher education (Zumbrunn et al., 2014), this study analyses cognitive, emotional and behavioural engagement in the higher education context.

The findings of our research have a number of implications for the design of business simulation games aimed at engaging students in the learning experience. We have concluded in this study that, in order to be engaged, it is important that students feel a sense of competence, autonomy, relatedness and self-efficacy while playing. To promote the experience of these self-system processes, prior studies have recommended the application of different game design elements. For instance, Xi and Hamari (2019) showed that achievement-related elements (e.g., points, leaderboards, progress graphs, etc.) are associated with higher levels of competence and autonomy. Therefore, it is recommended that business simulation games provide students with points at the end of each simulation to see their performance, leaderboards to compare their score to those of other players, and performance graphs that give them information about their progress over time. Similarly, Sailer et al. (2017) also showed that gamified systems with leaderboards and performance graphs foster competence and autonomy. Likewise, the need for relatedness has been associated with teammates (Sailer et al., 2017). Thus, business simulation games should be designed in groups of students that work together towards a shared objective. Besides cooperation, the need for relatedness has also been related to social competition (Xi and Hamari, 2019). In this regard, it would be beneficial to design business simulation games so that they can create friendly competition among groups of students to generate a sense of belonging (van Roy and Zaman, 2018). Finally, the activities that the players undertake as part of the games should be designed to provide students with a sense of self-efficacy.

As with any research, this study has limitations. First, the self-system model of motivational development suggests that motivational systems are organised around engagement and disaffection (Connell and Wellborn, 1991; Skinner et al. 2008). However, this study focuses on the analysis of different dimensions of engagement. Therefore, future research should also include measures of disaffection. Secondly, this 
research focuses on the study of personal factors as variables predicting engagement. However, previous studies have also identified contextual factors, such as autonomy support, goal structures, relationships with teachers and peers, the provision of structure and involvement (Connell and Wellborn, 1991; Skinner et al., 2009a). Therefore, future studies should analyse contextual variables. Thirdly, the model establishes that there are reciprocal effects between engagement and self-system beliefs. It would be interesting to analyse these reciprocal effects over time. Finally, students' learning was measured based on their perceptions (opinions) of learning. Thus, future research should also include other measures of learning, such as retention or transfer learning, measured objectively (e.g., students' grades, application tests) to further explore whether business simulation games influence learning.

\section{Conflict of Interest Statement}

The authors declare no conflict of interests. Data will be available on request.

\section{Ethics Statement}

The authors declare that they have taken steps to protect the participants, ensuring that they were not disadvantaged and that the data have been anonymised.

\section{References}

Bandura, A., (1977). Self-efficacy: Toward a Unifying Theory of Behavioral Change. Psychological Review, 84 (2), 191-215.

Baumeister, R., Leary, M., (1995). The need to belong: desire for interpersonal attachments as a fundamental human motivation. Psychology Bulletin, 117 (3), 497529.

Ben-Zvi, T., (2010). The efficacy of business simulation games in creating Decision Support Systems: An experimental investigation. Decision Support Systems, 49, 6169.

Borrajo, F., Bueno, Y., de Pablo, I., Santos, B., Fernández, F., García, J., Sagredo, I., (2010). SIMBA: A simulator for business education and research. Decision Support Systems, 48, 498-506. 
Carmines, E., Zeller, R., (1979). Reliability and validity assessment. In J. Sullivan \& R. Niemi (Eds.), Sage University Paper Series on Quantitative Applications in the Social Sciences. Beverly Hills and London: Sage Publications.

Caulfield, C., Maj, S., Xia, J., Veal, D., (2012). Shall we play a game? Modern Applied Science, 6 (1), 2-16.

Chin, W.W., (2010). How to write up and report PLS analyses. In Vinzi, V.E., Chin, W.W., Henseler, J., Wang, H. (Eds.). Handbook of Partial Least Squares (pp. 655690). Berlin: Springer.

Christenson, S. L., Reschly, A. L., Wylie, C., (2012). Handbook of research on student engagement. New York: Springer.

Connell, J. P., Wellborn, J. G., (1991). Competence, autonomy and relatedness: A motivational analysis of selfsystem processes. In M. Gunnar and L.A. Sroufe (Eds.), Minnesota Symposium on Child Psychology, Vol. 23: Self processes in development (pp. 43-77). Chicago, IL: University of Chicago Press.

de Charms, R. (1968). Personal Causation. New York: Academic Press.

Deci, E. (1975). Intrinsic motivation. New York: Plenum Press.

Doyle, D., Brown, F., (2000). Using a business simulation to teach applied skills - the benefits and the challenges of using student teams from multiple countries. Journal of European Industrial Training, 24, 330-336.

Dupont, S., Galand, B., Nils, F., Hospel, V., (2014). Social context, self-perceptions and student engagement: A SEM investigation of the self-system model of motivational development (SSMMD). Electronic Journal of Research in Educational Psychology, 12 (1), 5-32.

Eseryel, D., Law, V., Ifenthaler, D., Ge, X., Miller, R., (2014). An investigation of the interrelationships between motivation, engagement, and complex problem solving in game-based learning. Educational Technology \& Society, 17 (1), 42-53.

Fall, A., Roberts, G., (2012). High school dropouts: Interactions between social context, self-perceptions, school engagement, and student dropout. Journal of Adolescence, 35 (4), 787-798. 
Filak, V., Sheldon, K., (2008). Teacher support, student motivation, student need satisfaction, and college teacher course evaluations: testing a sequential path model. Educational Psychology, 28, 711-724.

Fitó-Bertran, A., Hernández-Lara, A., Serradell-López, E., (2014). Comparing student competences in a face-to-face and online business game. Computers in Human Behavior, 30, 452-459.

Fornell, C., Larcker, D., (1981). Evaluating structural equation models with unobservable variables and measurement error. Journal of Marketing Research, 18, 39-50.

Fredricks, J., Blumenfeld, P., Paris, A., (2004). School engagement: Potential of the concept, state of the evidence. Review of Educational Research, 74 (1), 59-109.

Fredricks, J., McColskey, W., (2012). The measurement of student engagement: A comparative analysis of various methods and student self-reports instruments. In S.L. Christenson et al. (Eds.), Handbook of Research on Student Engagement (pp. 763-782). Springer.

Furrer, C. J., Skinner, E. A., Pitzer, J. R., (2014). The influence of teacher and peer relationships on students' classroom engagement and everyday motivational resilience. National Society for the Study of Education, 113 (1), 101-123.

Galea, C., (2001). Experiential simulations: Using web-enhanced role-plays to teach applied business management. Information Technology and Management, 2, 473489.

Green, J., Liem, G. A. D., Martin, A. J., Colmar, S., Marsh, H. W., McInerney, D., (2012). Academic motivation, self-concept, engagement, and performance in high school: Key processes from a longitudinal perspective. Journal of Adolescence, 35 (5), 1111-1122.

Hair, J.F., Ringle, C.M., Sarstedt, M., (2011). PLS-SEM: Indeed a silver bullet. Journal of Marketing Theory and Practice, 19 (2), 139-152.

Hamari, J., Shernoff, D., Rowe, E., Coller, B., Asbell-Clarke, J., Edwards, T., (2016). Challenging games help students learn: An empirical study on engagement, flow and immersion in game-based learning. Computers in Human Behavior, 54, 170179. 
Henrie, C., Halverson, L., Graham, C. (2015). Measuring student engagement in technology-mediated learning: A review. Computers \& Education, 90, 36-53.

Lainema, T., Nurmi, S., (2006). Applying an authentic, dynamic learning environment in real world business. Computers \& Education, 47 (1), 94-115.

Lei, M., Clemente, I., Hu, Y. (2019). Student in shell: The robotic body and student engagement. Computers \& Education, 130, 59-80.

Loon, M., Evans, J., Kerridge, C., (2015). Learning with a strategic management simulation game: A case study. The International Journal of Management Education, 13, 227-236.

Matute, J., Melero, I., (2016). Game-based learning: Using business simulators in the university classroom. Universia Business Review, 13 (3), 72-91.

McGonigal, J., (2011). Reality Is Broken. New York: The Penguin Press.

Neys, J., Jansz, J., Tan, E., (2014). Exploring persistence in gaming: The role of selfdetermination and social identity. Computers in Human Behavior, 37, 196-209.

Nunnally, A., Bernstein, I., (1994). Psychometric theory, Ed. McGraw-Hill.

Pasin, F., Giroux, H., (2011). The impact of a simulation game on operations management education. Computers \& Education, 57, 1240-1254.

Pintrich, P., Smith, D., García, T., McKeachie, W., (1991). A manual for the use of Motivated Strategies for Learning Questionnaire (MSLQ). Ann Arbor, Michigan: The University of Michigan.

Reeve, J., (2013). How students create motivationally supportive learning environments for themselves: The concept of agentic engagement. Journal of Educational Psychology, 105 (3), 579-595.

Reeve, J., Tseng, C. M., (2011). Agency as a fourth aspect of students' engagement during learning activities. Contemporary Educational Psychology, 36 (4), 257-267.

Reinartz, W., Haenlein, M., Henseler, J., (2009). An empirical comparison of the efficacy of covariance-based and variance-based SEM. International Journal of Research in Marketing, 26, 332-344.

Ringle, C., Wende, S., Becker, J., (2015). SmartPLS 3. Bönningstedt: SmartPLS. 
Ryan, R., Rigby, C., Przybylski, A., (2006). The motivational pull of video games: A self-determination theory approach. Motivation and Emotion, 30 (4), 344-360.

Sailer, M., Hense, J., Mayr, S., Mandl, H. (2017). How gamification motivates: An experimental study of the effects of specific game design elements on psychological need satisfaction. Computers in Human Behavior, 69, 371-380.

Shen, B., McCaughtry, N., Martin, J., Fahlman, M., Garn, A., (2012). Urban highschool girls' sense of relatedness and their engagement in physical education. Journal of Teaching in Physical Education, 31 (3), 231-245.

Sinclair, M., Christenson, S., Lehr, C., Anderson, A., (2003). Facilitating student learning and engagement: Lessons learned from Check \& Connect longitudinal studies. The California School Psychologist, 8, 29-41.

Sitzmann, T., (2011). A meta-analytic examination of the instructional effectiveness of computer-based simulation games. Personnel psychology, 64 (2), 489-528.

Skinner, E., (2016). Engagement and disaffection as central to processes of motivational resilience and development. In K.R. Wentzel and D.B. Miele (Eds.), Handbook of Motivation at School (pp. 145-168). New York: Routledge.

Skinner, E., Furrer, C., Marchand, G., Kindermann, T., (2008). Engagement and disaffection in the classroom: Part of a larger motivational dynamic? Journal of Educational Psychology, 100 (4), 765-781.

Skinner, E. A., Kindermann, T. A., Connell, J. P., Wellborn, J. G., (2009a). Engagement as an organizational construct in the dynamics of motivational development. In K. Wentzel and A. Wigfield (Eds.), Handbook of motivation in school (pp. 223-245). Mahwah, NJ: Erlbaum.

Skinner, E. A., Kindermann, T. A., Furrer, C., (2009b). A motivational perspective on engagement and disaffection: Conceptualization and assessment of children's behavioral and emotional participation in academic activities in the classroom. Educational and Psychological Measurement, 69, 493-525.

Tiwari, S., Nafees, L., Krishnan, O., (2014). Simulation as a pedagogical tool: Measurement of impact on perceived effective learning. The International Journal of Management Education, 12, 260-270. 
Van Roy, R., Zaman, B. (2018). Unravelling the ambivalent motivational power of gamification: A basic psychological needs perspective. International Journal of Human-computer Studies (in press).

Vos, L., Brennan, R., (2010). Marketing simulation games: Student and lecturer perspectives. Marketing Intelligence \& Planning, 28, 882-897.

Wang, M. T., Peck, S. C., (2013). Adolescent educational success and mental health vary across school engagement profiles. Developmental Psychology, 49 (7), 12661276.

White, R., (1959). Motivation reconsidered: the concept of competence. Psychology Review, 66 (5), 297-333.

Wolters, C., (2004). Advancing achievement goal theory: Using goal structures and goal orientations to predict students' motivation, cognition, and achievement. Journal of Educational Psychology, 96, 236- 250.

Xi, N., Hamari, J. (2019). Does gamification satisfy needs? A study on the relationship between gamification features and intrinsic need satisfaction. International Journal of Information Management, 46, 210-221.

Xie, K., Heddy, B., Greene, B. (2019). Affordances of using mobile technology to support experience-sampling method in examining college students' engagement. Computers \& Education, 128, 183-198.

Zumbruun, S., McKim, C., Buhs, E., Hawley, L., (2014). Support, belonging, motivation, and engagement in the college classroom: a mixed method study. Instructional Science, 42 (5), 661-684. 